\title{
Prevalence and Factors Associated with Leishmania infantum Infection of Dogs from an Urban Area of Brazil as Identified by Molecular Methods
}

\author{
Wendel Coura-Vital ${ }^{1,2}$, Marcos José Marques ${ }^{3}$, Vanja Maria Veloso ${ }^{4}$, Bruno Mendes Roatt ${ }^{2}$, Rodrigo Dian \\ de Oliveira Aguiar-Soares ${ }^{2}$, Levi Eduardo Soares Reis ${ }^{2}$, Samuel Leôncio Braga ${ }^{2}$, Maria Helena Franco \\ Morais ${ }^{1,5}$, Alexandre Barbosa Reis ${ }^{2}$, Mariângela Carneiro ${ }^{1,6 *}$ \\ 1 Departamento de Parasitologia, Instituto de Ciências Biológicas, Universidade Federal de Minas Gerais, Belo Horizonte, Minas Gerais, Brazil, 2 Núcleo de Pesquisas em \\ Ciências Biológicas, Instituto de Ciências Exatas e Biológicas, Universidade Federal de Ouro Preto, Ouro Preto, Minas Gerais, Brazil, 3 Departamento de Ciências Biológicas, \\ Universidade Federal de Alfenas, Alfenas, Minas Gerais, Brazil, 4 Departamento de Farmácia, Escola de Farmácia, Universidade Federal de Ouro Preto, Ouro Preto, Minas \\ Gerais, Brazil, 5 Gerência Regional de Controle de Zoonoses, Secretaria Municipal de Saúde, Prefeitura de Belo Horizonte, Belo Horizonte, Minas Gerais, Brazil, 6 Pós- \\ Graduação em Infectologia e Medicina Tropical, Faculdade de Medicina, Universidade Federal de Minas Gerais, Belo Horizonte, Minas Gerais, Brazil
}

\begin{abstract}
Background: Various factors contribute to the urbanization of the visceral leishmaniasis (VL), including the difficulties of implementing control measures relating to the domestic reservoir. The aim of this study was to determine the prevalence of canine visceral leishmaniasis in an urban endemic area in Brazil and the factors associated with Leishmania infantum infection among seronegative and PCR-positive dogs.

Methodology: A cross-sectional study was conducted in Belo Horizonte, Minas Gerais, Brazil. Blood samples were collected from 1,443 dogs. Serology was carried out by using two enzyme-linked immunosorbent assays (Biomanguinhos/FIOCRUZ/ RJ and "in house"), and molecular methods were developed, including PCR-RFLP. To identify the factors associated with early stages of infection, only seronegative $(n=1,213)$ animals were evaluated. These animals were divided into two groups: PCR-positive $(n=296)$ and PCR-negative $(n=917)$ for $L$. infantum DNA. A comparison of these two groups of dogs taking into consideration the characteristics of the animals and their owners was performed. A mixed logistic regression model was used to identify factors associated with $L$. infantum infection.
\end{abstract}

Principal Findings: Of the 1,443 dogs examined, 230 (15.9\%) were seropositive in at least one ELISA, whereas PCR-RFLP revealed that 356 animals (24.7\%) were positive for $L$. infantum DNA. Results indicated that the associated factors with infection were family income $<$ twice the Brazilian minimum salary $(\mathrm{OR} 2.3 ; 95 \% \mathrm{Cl} 1.4-3.8)$, knowledge of the owner regarding the vector $(\mathrm{OR} 1.9 ; 95 \% \mathrm{Cl} 1.1-3.4)$, the dog staying predominantly in the backyard $(\mathrm{OR} 2.2 ; 95 \% \mathrm{Cl} 1.1-4.1)$, and a lack of previous serological examination for VL (OR 1.5; 95\% Cl 1.1-2.3).

Conclusions: PCR detected a high prevalence of $L$. infantum infection in dogs in an area under the Control Program of VL intervention. Socioeconomic variables, dog behavior and the knowledge of the owner regarding the vector were factors associated with canine visceral leishmaniasis (CVL). The absence of previous serological examination conducted by the control program was also associated with $L$. infantum infection. It is necessary to identify the risk factors associated with CVL to understand the expansion and urbanization of VL.

Citation: Coura-Vital W, Marques MJ, Veloso VM, Roatt BM, Aguiar-Soares RDdO, et al. (2011) Prevalence and Factors Associated with Leishmania infantum Infection of Dogs from an Urban Area of Brazil as Identified by Molecular Methods. PLoS Negl Trop Dis 5(8): e1291. doi:10.1371/journal.pntd.0001291

Editor: Marleen Boelaert, Institute of Tropical Medicine, Belgium

Received January 21, 2011; Accepted July 13, 2011; Published August 16, 2011

Copyright: ( $) 2011$ Coura-Vital et al. This is an open-access article distributed under the terms of the Creative Commons Attribution License, which permits unrestricted use, distribution, and reproduction in any medium, provided the original author and source are credited.

Funding: This study was supported by the DECIT/MS/CNPq/BR/grant 576062/2008-1, FAPEMIG/BR/grant CBB - APQ-3073-4.01/07, CNPq/BR/grant 472554/2007-7 and PPSUS/MS/CNPq/FAPEMIG/SES-MG/grant CBB-APQ-00356-10. ABR and MC are grateful to the CNPq for fellowships. The FAPEMIG sponsored WCV scholarships (Doctor Degree - Programa de Pós-Graduação em Parasitologia, Universidade Federal de Minas Gerais). The funders had no role in the study design, data collection and analysis, decision to publish, or preparation of the manuscript.

Competing Interests: The authors have declared that no competing interests exist.

* E-mail: mcarneir@icb.ufmg.br

\section{Introduction}

Human visceral leishmaniasis (HVL) constitutes a public health problem that affects millions of people throughout the world [1]. Over the past decade, there has been an average of 3379 cases of HVL per year in Brazil, with an incidence of 1.9 cases per 100,000 inhabitants [2]. During this period, however, an increase in the prevalence of the disease has been observed in several urban areas, and this phenomenon may be attributed to high population density, increased migration, environmental changes, inadequate living conditions and vector adaptation [1,3].

In South America and Europe, the causative agent of HVL is Leishmania (Leishmania) infantum, a protozoan parasite transmitted by sand flies of the Phlebotominae family, which are widely 


\section{Author Summary}

Visceral leishmaniasis (VL) is a disease caused by the parasite Leishmania infantum, and dogs are the most important domestic reservoirs of the agent. During recent decades, VL has expanded to large Brazilian urban centers. In the present work, we have demonstrated by using molecular techniques that the rate of canine infection as detected by serology has been considerably underestimated. Two groups of seronegative dogs (infected and non-infected according to molecular methods) were further evaluated from data obtained through interviews with owners of the animals. The factors associated with Leishmania infection in dogs were a family income of less than two minimum salaries, the knowledge of the owner regarding the vector, the dog spending most of its time in the backyard and the dog never having had a previous serological examination. Awareness regarding the factors associated with canine infection will improve health services and the understanding of the disease's expansion in urban areas.

distributed in both wild and domestic surroundings [4]. Dogs are the main urban reservoirs and represent the major source of contagion for the vector by virtue of their high prevalence of infection and intense cutaneous parasitism [5]. Furthermore, it has been estimated that more than $50 \%$ of seropositive dogs are asymptomatic [6] and may remain free of clinical symptoms for several years or even throughout life [7].

The prevalence of canine visceral leishmaniasis (CVL) in endemic areas of Brazil ranges between 5.9 and 29.8\% [8-13], although the serological methods employed in the detection of CVL exhibit low sensitivities and may underestimate the true value [14-15]. The Brazilian Ministry of Health, through the Control Program of Visceral Leishmaniasis (CPVL), has instituted specific measures to control the dissemination of the disease, and these include early diagnosis and treatment of human cases, identification and elimination of seropositive infected dogs, control of insect vectors and health education [2]. To date, however, the actions of CPVL have had little impact, and this negative outcome has been ascribed to delays in detecting and eliminating infected dogs, the tendency to replace infected dogs by susceptible puppies, and the low sensitivity of the available serological methods [16-18].

Although serological techniques lack the sensitivity required to detect Leishmania in the initial stages of infection, polymerase chain reaction (PCR) based assays can disclose the presence of protozoan DNA very early on, even before seroconversion [19-20]. Epidemiological studies employing modern molecular techniques have revealed that the prevalence of CVL in endemic areas in Europe is far greater than serological methods had previously suggested [15,21-22]. According to De Andrade et al. [14], it is possible that as many as $62 \%$ of Brazilian dogs showing negative serological and parasitological tests for $L$. infantum would be classified as CVL-positive according to PCR and restriction fragment length polymorphism (RFLP) assays. A cohort study conducted by Oliva et al. [20] showed that most of the animals had PCR-positive results months before seroconversion. In addition, experimentally infected dogs have been found to be positive by conjunctival PGR by 45 days of infection [23].

To understand the expansion and urbanization of VL, it is necessary to identify the risk factors associated with human and/or canine infection. A number of publications have considered the factors influencing HVL [24-26], but the potential risk factors of the canine disease have received far less attention. Information concerning animal susceptibility and its association with race, size, type of hair and age is available [8,27-28]. However, factors relating to the domiciliary and peridomiciliary environment, the socioeconomic status of the owner, the type of care provided for the animal, and specific animal behavior must be investigated to explain the importance of dogs in the maintenance of CVL in urban areas.

In view of the aforementioned problems an investigation was undertaken to look into the prevalence of $L$. infantum infection using PCR followed by RFLP and serological methods (ELISA). The factors associated with $L$. infantum infection among seronegative (determined by enzyme-linked immunosorbent assay ELISA) and PCR-RFLP-positive dogs were also assessed. The L. infantum infection criterion proposed herein prioritizes CVL early onset. This study was conducted in Belo Horizonte, the capital of the State of Minas Gerais, located in Southeastern Brazil, which is considered an area of active transmission [29].

\section{Methods}

\section{Ethical statement}

The study was approved by the Committees of Ethics in Animal Experimentation of the Universidade Federal de Ouro Preto (protocol no. 083/2007), of the Universidade Federal de Minas Gerais (protocol no. 020/2007), and of the City Council of Belo Horizonte (protocol no. 001/2008). All procedures in this study were according to the guidelines set by the Brazilian Animal Experimental Collage (COBEA), Federal Law number 11794. Owners of the dogs participating in the project were informed of the research objectives and were required to sign the Informed Consent Form before sample and data collection.

\section{Study design}

The cross-sectional study was conducted in 2008 in the northwest sanitary district of Belo Horizonte, which covers an area of $36.874 \mathrm{~km}^{2}$ (Fig. 1). According to the census by the Instituto Brasileiro de Geografia e Estatística in 2007, the human population of this area is 360,000 . The canine population comprised 20,883 animals, according to the Zoonosis Control Management of the northwest sanitary district. At the time of the study, the prevalences of CVL in Belo Horizonte and its northwest sanitary district were 7.6 and $7.8 \%$, respectively [30]. With an expected prevalence of CVL in the study area of between 5 and 10\%, the 95\% confidence interval, and an estimated precision of $1.5 \%$, the appropriate sample size for the study was calculated to be approximately 1500 animals. Because of the high prevalence of seropositive dogs and the presence of human cases, the activities of the CPVL, including canine surveys (diagnosis and culling seropositive dogs), have been carried out in the study area annually. The present field work was done in close collaboration with the Municipality Health Service, and the data were collected during the canine survey census, conducted by the health agents, as part of CVLP's routine. The studied area was selected within the northwest sanitary district by convenience and was chosen because at that moment (2008) a canine survey was beginning in this area. The households visited by the CVLP in an area that comprised of 37 census tracts (according to the Brazilian Institute of Geography and Statistics) [31] were included in the present study. A total of 918 households were included in this study, and all dogs within selected houses were sampled.

\section{Collection of data}

A trained research team interviewed the owners of the study animals using a previously tested, structured questionnaire that sought information regarding the following groups of variables: (i) 


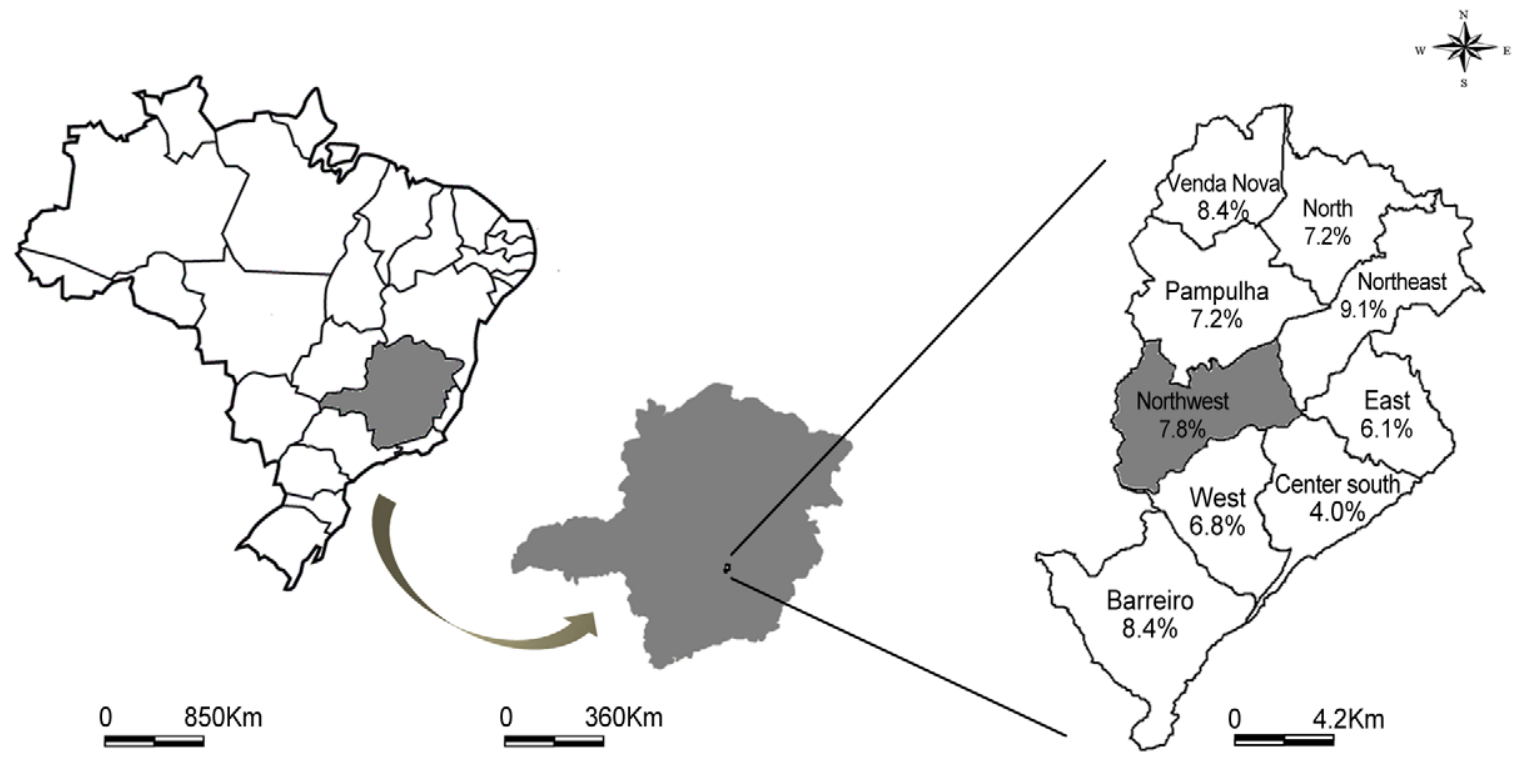

Figure 1. Municipality of Belo Horizonte, state of Minas Gerais, Brazil, subdivided into sanitary areas. doi:10.1371/journal.pntd.0001291.g001

knowledge about the disease (i.e., form of transmission and clinical signs of HVL); (ii) knowledge about the vector (characteristics and presence in the domicile and peridomicile); (iii) knowledge about the host (epidemiological importance of the host, clinical signs of leishmaniasis, and care of the dog); (iv) socioeconomic characteristics of the owner (per capita/family income, and schooling); (v) characteristics of the domicile, annexes and surroundings [i.e., structure of roof, floor and walls; number of rooms, including bedrooms; number of residents; presence of trees (particularly banana trees); rubble; exposed garbage; dead leaves; and vegetable garden]; (vi) method of garbage disposal (collected, burnt or buried); and (vii) presence of other domestic animals (birds, cats and cattle). The knowledge about the disease was validated according to selfreporting of the mainly symptoms of LVG and LVH. Vector recognition was acknowledged by self-reporting and validated by the showing of different diptera species samples (Lutzomyia longipalpis and Aedes aegypti) to the participants. The following information on the dogs was collected on an appropriate form: age, sex, size, hair type, breed, behavior (habits related to the place where the dog sleeps spends most of its time, i.e. in the street, in the residence, in the backyard), dog care, clinical examinations, past history of vaccination and serological exams previous to leishmaniasis. Some characteristics were defined by the health agents, such as breed, dog size, hair type and clinical evaluation. These characteristics are routinely obtained and registered in a standardized form used by CPVL in the canine survey. The hair type was defined according to the breed, i.e., collie was classified as long-furred hair, Doberman as short-furred. Dog size also was defined according to the breed, i.e., pinscher was categorized as small size, poodle as medium size and German shepherd as large size. According to the absence/presence of clinical infection signs, the dogs were categorized as asymptomatic, with no signs suggestive of disease, and symptomatic, with characteristic clinical signs of visceral leishmaniasis, such as opaque bristles, severe loss of weight, onychogryphosis, cutaneous lesions, apathy and keratoconjunctivitis.

\section{Collection of blood samples}

A sample of peripheral blood $(5 \mathrm{~mL})$ was collected by puncture of the brachiocephalic vein and an aliquot transferred to a glass vial containing sufficient anticoagulant (ethylenediaminetetraacetic acid; EDTA) to give a final concentration of $1 \mathrm{mg} / \mathrm{mL}$. The blood sample was centrifuged $(1500-1800 \times g, 20 \mathrm{~min})$, the buffy coat containing the leukocytes removed, resuspended in $10 \mathrm{mM}$ Tris$\mathrm{HCl}$ buffer (supplemented with $1 \mathrm{mM}$ EDTA) in the proportion of 1:1, and stored at $-80^{\circ} \mathrm{C}$ until required for PCR-RFLP. The remaining portion of the blood sample was transferred to two separate filter papers for subsequent analysis by enzyme-linked immunosorbent assay (ELISA).

\section{Enzyme-linked immunosorbent assay}

ELISA was performed in parallel in the Laboratory of Immunopathology of Universidade Federal de Ouro Preto (LIMP) and the Laboratory of Zoonosis of the Prefeitura Municipal de Belo Horizonte (LZOON). The presence of IgG against Leishmania in blood samples was determined using an "in-house" ELISA procedure performed at the LIMP. Soluble Leishmania chagasi (MHOM/BR/1070/BH46) antigen (SLA) was prepared by the method of Reis et al. [32] from promastigotes harvested from stationary-phase liver infusion tryptose cultures. The concentration of protein in the SLA solution was determined as previously described [33] and adjusted to $1000 \mu \mathrm{g} / \mathrm{mL}$. Diluted SLA was divided into small portions and stored at $-70^{\circ} \mathrm{C}$ until required for assay.

In the ELISA procedure, 96-well MaxiSorp ${ }^{\mathrm{TM}}$ microplates (Nalge Nunc Int., Rochester, NY, USA) were coated with SLA $(2 \mu \mathrm{g} /$ well $)$ and maintained overnight at $4-8^{\circ} \mathrm{C}$. Wells were then washed, and eluates from blood dried on filter paper were added at 1:80 dilution. To perform the reaction, filter paper was thawed and 5 - $\mu \mathrm{m}$-diameter spots eluted in casein-PBS for testing by ELISA. The wells were washed again prior to the addition of peroxidase-conjugated sheep anti-dog IgG (anti-heavy chain specific; Bethyl Laboratories Inc., Montgomery, TX, USA). After further washes, chromogenic substrate $(O$-phenylenediamine; Sigma-Aldrich, St. Louis, MO, USA) was added, and the absorbance was read on an automatic EL 800G ELISA microplate reader (Bio Tek Instruments, Winooski, VT, USA) at $492 \mathrm{~nm}$. The anti-IgG conjugate concentration employed (1:16,000 dilution) was determined by a block titration method employing 
positive and negative standard sera. The cut-off value was established as the mean absorbance value +2 SD from 20 eluates from blood of uninfected dogs dried on filter paper.

Duplicate filter papers were submitted to ELISA at LZOON using a kit developed by Fundação Oswaldo Cruz, EIE - Ensaio Imunoenzimático para diagnostico da leishmaniose visceral canina BioManguinhos (Rio de Janeiro, RJ, Brazil) and applied according to the supplier's instructions.

\section{Molecular methods (PCR-RFLP)}

DNA was extracted from buffy coat fractions using Wizard ${ }^{\mathrm{TM}}$ Genomic DNA purification kits (Promega, Madison, WI, USA) according to the manufacturer's instructions. The primers used to amplify the conserved region of the Leishmania kDNA minicircle were as follows: forward: 5'-GGG (G/T)AG GGG CGT TGT (G/C)CG AA-3'; reverse: 5'-(G/G)(G/C)(G/G) (A/T)CT AT(A/ T) TTA CAC CAA CGG G-3' [34]. The reaction mixture consisted of $1 \times$ buffer [10 mM Tris-HCl, $50 \mathrm{mM} \mathrm{KCl}(\mathrm{pH}$ 8.8)], $1.5 \mathrm{mM} \mathrm{MgCl}_{2}, 2.0 \mu \mathrm{M}$ dNTP, 1.0 pmol of each primer, $0.76 \mathrm{U}$ of Taq polymerase (Sinapse, São Paulo, SP, Brazil), $2.5 \mu \mathrm{L}$ DNA and Milli Q water to a final volume of $12.5 \mu \mathrm{L} /$ well $\left(\right.$ MicroAmp ${ }^{\circledR}$ Fast Optical 96-Wells, Applied Biosystems, Foster City, CA, USA). PCR reactions were performed in a 96-well Verit Thermal Cycler (Applied Biosystems) using the following program: initial denaturation at $94^{\circ} \mathrm{C}$ for $1 \mathrm{~min}$, followed by 40 cycles of $30 \mathrm{~s}$ at $93^{\circ} \mathrm{C}$, $1 \mathrm{~min}$ at $64^{\circ} \mathrm{C}$ and $1 \mathrm{~min}$ at $72^{\circ} \mathrm{C}$, with a final extension at $72^{\circ} \mathrm{C}$ for $7 \mathrm{~min}$. DNA from L. chagasi (strain MHOM/BR/1972/BH46), obtained from the DNA reference library at LIMP, was used as positive control, while DNA from non-infected dogs, raised in the experimental kennels at UFOP, was used as negative control.

PCR amplicons $(5 \mu \mathrm{L})$ were digested for $3 \mathrm{~h}$ at $37^{\circ} \mathrm{C}$ in $1 \mathrm{U}$ of Hae III (Invitrogen, Carlsbad, CA, USA) in $1 \times$ buffer $[10 \mathrm{mM}$ Tris-HCl, $10 \mathrm{mM} \mathrm{MgCl} 2(\mathrm{pH} 7.5)]$ and Milli $Q$ water to a final volume of $15.0 \mu \mathrm{L} /$ well (MicroAmp ${ }^{\circledR}$ Fast Optical 96-Well, Applied Biosystems) [35]. Restriction fragments, together with a 25 bp DNA ladder (Invitrogen), were electrophoresed in 10\% polyacrylamide gels at $40 \mathrm{~mA}$ in $89 \mathrm{mM}$ Tris base $(\mathrm{pH} 8.0$ ), $89 \mathrm{mM}$ boric acid and $2 \mathrm{mM}$ EDTA. Bands were detected by silver staining, and the patterns were compared with those obtained using DNA from L. (L.) amazonensis (MHOM/BR/ 1973/M2269), L. (Viannia) braziliensis (MHOM/BR/1975/M2903) and L. (L.) chagasi (MHOM/BR/1972/BH46) from the DNA reference library at LIMP. Samples with very faint bands in PCR were extracted again and assayed by PCR to obtain better bands in the RFLP profile. All samples that did not show similar profiles to $L$. infantum DNA were excluded from the present study.

\section{Animal groups}

Dogs were classified as seronegative if ELISA results were negative in both laboratories (LIMP and LZOON). The seronegative animals were categorized as (i) infected group: animals presenting positive PCR-RFLP for L. infantum; and (ii) non-infected group; animals presenting negative PCR-RFLP for $L$. infantum. These two groups were analyzed to identify factors associated with infection.

\section{Statistical analysis}

Databases were generated using EpiData version 3.2 (EpiData Association, Odense, Denmark) by double entry of the results, and they were subsequently corrected, compared and analyzed using STATA version 11.0 software (Stata Corp., College Station, TX, USA).

To investigate the factors potentially associated with $L$. infantum infection, the infected and non-infected groups of animals were compared. A mixed logistic regression model [36] was employed to evaluate the association between the independent and dependent variables. This model was chosen on the basis that the sampling process included all dogs within a studied household, and it incorporated the underlying assumption that observations obtained from dogs in the same household were mutually dependent while observations from dogs in different households were independent. The xtmlogit function provide by Stata was used to perform the analysis and the household was included as a random effect.

Univariate analysis using the mixed logistic regression model was conducted for all variables collected, and those that attained a $\mathrm{p}$ value $<0.25$ were included in the multivariate models. Hierarchical analysis levels were established on the basis of a hypothetical canine infection model that took into account the collected variables. The inclusion of variables in the model was based on a conceptual framework describing the hierarchical relationships between risk factors and canine $L$. infantum infection [37]. The variables were grouped in four levels: socioeconomic conditions; household and outside-home conditions; knowledge of vector and host; and dog characteristics and behavior (Fig. 2). Variables with a significance of $\mathrm{p}<0.15$ in each hierarchical level were maintained in the next level. Variables presenting statistical significance at each level but with either collinearity or low frequency were excluded from the multivariate analysis, while categorical variables were transformed into dummy variables. Backward analyses were used to construct intermediate and final models, and likelihood ratio tests were used to adjust these models. Variables with significance levels of $\mathrm{p}<0.05$ were maintained in the final model.

\section{Results}

Serological and molecular diagnosis of the study animals

Of the 1443 dogs studied, 230 (15.9\%, 95\% CI 14.1-17.9) were seropositive according to at least one ELISA. The results in each laboratory were 12\% (LIMP) and 9.4\% (LZOON). PCR-RFLP analyses revealed that $356(24.7 \%$; 95\% CI 22.5-26.0) of the dogs studied were positive for $L$. infantum DNA. Only three showed molecular bands similar to $L$. braziliensis, and they were not included in the present study.

Among 1087 PGR-negative and 356 PCR-positive animals, 170 dogs $(15.6 \%)$ and $60 \operatorname{dogs}(16.8 \%)$, respectively, were seropositive in at least one ELISA. To investigate factors associated with $L$. infantum infection, those animals that were positive in at least one ELISA test $(\mathrm{n}=230)$ were excluded. Therefore, among the 1.213 seronegative dogs, two groups were set up, according to PCRRFLP: $296(24.4 \%)$ positive and 917 (75.6\%) negative.

\section{Characteristics of the dogs}

Within the group of 1213 dogs included in the evaluation of associated factors, female $(53.7 \%)$, medium-sized $(52.3 \%)$ and short-haired $(54.7 \%)$ animals predominated. The mean age was 54.2 months (SD 39.8), and the median was 48 months (IQR 24; 84). Most of the dogs $(58.9 \%)$ had received a check-up by a veterinarian. The majority of the animals (97.6\%) were asymptomatic (no signs suggestive of disease), and most (52.6\%) had been acquired within the neighborhood of the owner's residence. Generally, the animals lived and slept in the backyard (83.7 and $77.7 \%$, respectively), rather than inside the residence.

\section{Knowledge of the owners about the disease}

Of the $918 \mathrm{dog}$ owners who were interviewed, 903 (98.4\%) had some knowledge about leishmaniasis, and of these, $533(59.0 \%)$ 


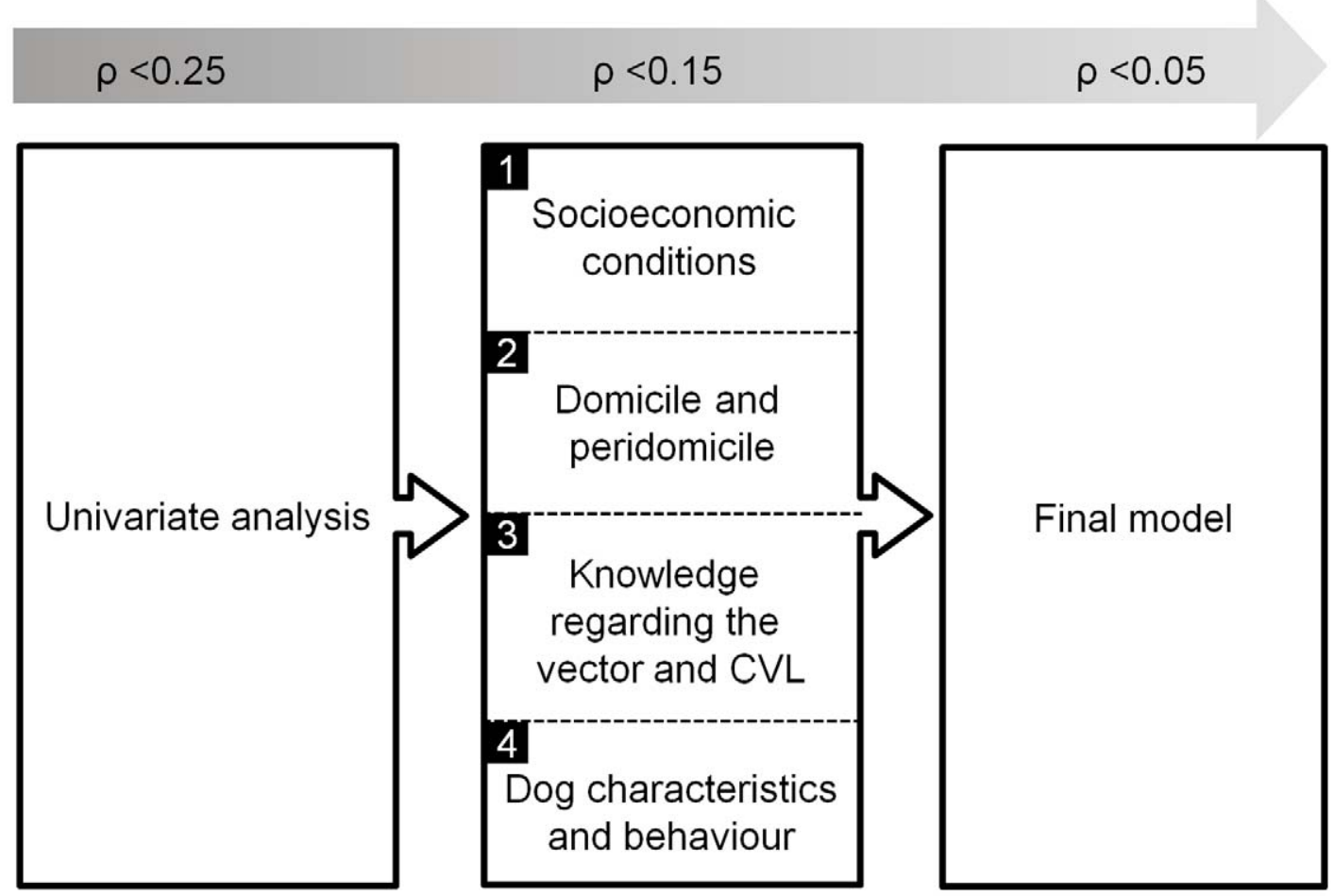

Figure 2. Hierarchical framework of risk factors for Leishmania infantum infection in dogs. doi:10.1371/journal.pntd.0001291.g002

knew about the forms of transmission. However, despite this rather widespread awareness, only 201 owners $(21.9 \%)$ were familiar with the symptoms of HVL, and only $103(11.2 \%)$ claimed to have knowledge of the vector of Leishmania. Around 4\% of owners had seen the vector in their domicile and/or peridomicile. Concerning CVL, 328 owners $(35.7 \%)$ stated that they were aware of the importance of dogs in the transmission of leishmaniasis, and 417 $(45.4 \%)$ declared that they knew the symptoms of the disease in the dog. When asked about their views if their pet were found to be infected with Leishmania, $75.1 \%$ of owners stated that they would authorize euthanasia. Interestingly, of the 209 owners (22.8\%) who had dogs with GVL in the past, $162(77.5 \%)$ consented to euthanasia of their animal, whereas $37(17.7 \%)$ sought treatment for their pet. At least one case of CVL had been recorded in the vicinity (same block) of many $(49.5 \%)$ of the residences evaluated (data not shown).

\section{Housing conditions}

A total of 918 households were selected. They had a mean of 1.57 (SD 1.17) dogs per household (1-9 dogs/house) and median of 1 (IQR 1; 2). The majority of the dwellings (563; 61.3\%) were detached houses, while $873(95.1 \%)$ had plastered walls, 754 $(82.1 \%)$ had a garden and $909(99.0 \%)$ were served by main sewage. Garbage was collected three or more times per week from $860(93.7 \%)$ residences. The mean numbers (SD) of rooms and bedrooms per house were 7.2 (SD 2.8) and 2.7 (SD 1.0), respectively. Each dwelling had an average of 3.8 (SD 1.8) residents.

\section{Risk factors associated with $L$. infantum infection}

A comparison between the infected $(n=296)$ and non-infected $(n=917)$ groups of animals was performed by multivariate analysis using the variables obtained from the interviews with owners and the records of individual dogs. The results of preliminary selection of the variables from the univariate analysis $(\mathrm{p}<0.25)$ are shown in Tables 1 and 2. The variables selected to build the final model $(p<0.15)$ were knowledge of the owner regarding the vector (yes/ no), knowledge of bite from the vector (yes/no), house treated with insecticide (no/yes), family income $(<2$ minimum salary/2-3 minimum salary/ $>3$ minimum salary), type of floor in the residence (other materials/tiles or wood), type of neighborhood (houses/houses with garden/lands), origin of $\operatorname{dog}$ (another district/ present neighborhood), dog stays predominantly in the backyard (yes/no), where the dog sleeps (indoors/outdoors), and lack of previous CVL serological examination (no/yes).

Infection with $L$. infantum (as detected by PCR-RFLP) was associated with a family income of less than twice the minimum salary (OR 2.3; 95\% CI 1.4-3.8), knowledge of the owner regarding the vector (OR 1.9; 95\% CI 1.1-3.4), dog staying predominantly in the backward (OR 2.2; 95\% CI 1.1-4.1) and lack of previous CVL serological examination (OR 1.5; 95\% CI 1.1-2.3) (Table 3).

\section{Discussion}

The results in the present investigation show that the prevalence of $L$. infantum infection in dogs as determined by PCR-RFLP $(24.7 \%)$ is higher than that detected by serology $(15.9 \%)$. Such divergent values are highly significant because they demonstrate that the magnitude of CVL in this study area, which is under constant CPVL intervention, has been underestimated. Factors associated with early L. infantum infection (PCR-RFLP+) were the socioeconomic conditions of the owner, the behavior of the dog, knowledge of the owner regarding the vector and the care the dogs had received. These results are relevant because they allow better understanding of the transmission of VL in a large city such as Belo Horizonte where leishmaniasis is expanding [29,38]. 
Table 1. Distribution of seronegative dogs $(n=1213)$ according to the characteristics of the animals, Brazil 2008.

\begin{tabular}{|c|c|c|c|c|}
\hline \multirow[t]{2}{*}{ Variable } & \multicolumn{2}{|l|}{ PCR-RFLP } & \multirow[t]{2}{*}{$\begin{array}{l}\text { Univariate analysis } \\
\text { Odds Ratio } \\
(95 \% \mathrm{Cl})\end{array}$} & \multirow[t]{2}{*}{$\rho$ values } \\
\hline & $\begin{array}{l}\text { Positive } \\
n(\%)\end{array}$ & $\begin{array}{l}\text { Negative } \\
n(\%)\end{array}$ & & \\
\hline \multicolumn{5}{|l|}{ Hair } \\
\hline Short & $173(58.5)$ & $491(53.5)$ & & \\
\hline Long & $123(41.5)$ & $426(46.5)$ & $1.2(0.9-1.7)$ & 0.17 \\
\hline \multicolumn{5}{|l|}{ Veterinary check ups } \\
\hline Yes & $151(55.3)$ & $527(59.4)$ & & \\
\hline No & $122(44.7)$ & $360(40.6)$ & $0.8(0.6-1.1)$ & 0.25 \\
\hline \multicolumn{5}{|l|}{ Symptomatic } \\
\hline Yes & $4(1.4)$ & $25(2.7)$ & & \\
\hline No & $292(98.6)$ & $890(97.3)$ & $0.4(0.1-1.5)$ & 0.20 \\
\hline \multicolumn{5}{|l|}{ Origin of the animal } \\
\hline District of residence & $154(56.2)$ & $459(51.6)$ & & \\
\hline Other district & $120(43.8)$ & $431(48.4)$ & $0.8(0.6-1.1)$ & 0.16 \\
\hline \multicolumn{5}{|c|}{ Dog staying predominantly in the backyard } \\
\hline No & $36(13.1)$ & $153(17.2)$ & & \\
\hline Yes & $238(86.9)$ & $737(82.8)$ & $1.4(0.9-2.3)$ & 0.10 \\
\hline \multicolumn{5}{|l|}{ Sleeping place } \\
\hline Inside the house & $51(18.6)$ & $208(23.4)$ & & \\
\hline In the garden & $223(81.4)$ & $682(76.6)$ & $1.4(1.0-2.1)$ & 0.08 \\
\hline \multicolumn{5}{|c|}{ CVL sorological examination previously } \\
\hline Yes & $183(68.8)$ & $662(76.1)$ & & \\
\hline No & $83(31.2)$ & $208(23.9)$ & $1.5(1.1-2.2)$ & 0.02 \\
\hline \multicolumn{5}{|l|}{ Age } \\
\hline$\leq 24$ months & $108(36.5)$ & $292(31.8)$ & & \\
\hline$>24$ and $\leq 84$ months & $116(39.2)$ & $411(44.8)$ & $0.7(0.5-1.0)$ & 0.08 \\
\hline$>84$ months & $72(24.3)$ & $214(23.3)$ & $0.9(0.6-1.3)$ & 0.59 \\
\hline
\end{tabular}

Moreover, the diagnosis of canine infection by $L$. infantum was achieved through the application of PCR-RFLP, which indicated the early onset of CVL. Additionally, as the data originated directly from dog owners and their respective animals, it was possible to perform a detailed analysis of a range of information and to determine the factors associated with CVL.

Studies in European endemic areas have also demonstrated an elevated prevalence of infection (typically $60-80 \%$ ) by PCR in comparison with that indicated by serology (generally $<30 \%$ ) $[15,39]$. Species identification was essential, especially because Belo Horizonte is an area of the simultaneous occurrence of cutaneous and visceral leishmaniasis and the dog can be host for both parasites [40]. Among the examined samples, only three showed molecular bands similar to L. braziliensis, and they were not included in the present study. Approximately a quarter of seronegative dogs were infected by $L$. infantum according to PCR-RFLP. These false-negative animals were likely within an "immunological window" that occurs prior to seroconversion, during which period B lymphocytes do not secrete polyclonal antibodies, and consequently, serological methods are less sensitive at this stage of the infection [41].

It is possible that false-negative dogs remain in the community as undisclosed reservoirs and, thus, interfere with the effectiveness of control measures. Indeed, despite recent intense efforts to eliminate seropositive dogs, no reduction in the incidence of HVL or CVL has been observed in urban areas [42]. Little is known if seronegative/PCR-positive dogs are immunologically resistant to Leishmania [43] or if they will develop the disease. However, it is possible to state that such animals have had previous contact with the parasite. Such information is relevant because canine positivity for Leishmania is included among the indicators for the prioritization of target control areas by the Ministry of Health. Although molecular biology methods are more promising in identifying infection, their use in the field requires further standardization and optimization.

HVL is favored by precarious socioeconomic and housing conditions, migratory movements and the presence of vector and reservoir in the domestic environment [24-26,44]. However, little is known about the risk factors that facilitate Leishmania infection in the main reservoir of the disease, namely, the domestic dog. To obtain a better understanding of these factors, comparisons were made between non-infected (seronegative/PCR-RFLP negative) animals and those infected (seronegative and PCR-RFLP positive). The decision to use PCR-RFLP-positive and seronegative animals was due to the detection of $L$. infantum in the initial stage of infection before seroconversion [19-20].

Regarding socioeconomic conditions of the owner, animals belonging to families with incomes of less than twice the minimum 
Table 2. Distribution of owners $(n=918)$ of seronegative dogs according to the socioeconomic and environmental conditions and understanding of the disease, Brazil 2008.

\begin{tabular}{|c|c|c|c|c|}
\hline \multirow[t]{2}{*}{ Variable } & \multicolumn{2}{|l|}{ PCR-RFLP } & \multirow[t]{2}{*}{$\begin{array}{l}\text { Univariate analysis } \\
\text { Odds Ratio }(95 \% \mathrm{Cl})\end{array}$} & \multirow[t]{2}{*}{$\rho$ values } \\
\hline & Positive (\%) & Negative (\%) & & \\
\hline \multicolumn{5}{|l|}{ Socioeconomic conditions } \\
\hline \multicolumn{5}{|l|}{ Family income } \\
\hline$>3$ minimum wages* & $72(54.1)$ & $281(65.8)$ & & \\
\hline 1 to 3 minimum wages & $24(18.1)$ & $88(20.6)$ & $0.9(0.6-1.5)$ & 0.78 \\
\hline$<1$ minimum wages & $37(27.8)$ & $58(13.6)$ & $2.4(1.5-3.9)$ & 0.00 \\
\hline \multicolumn{5}{|l|}{ Schooling } \\
\hline University & $49(24.5)$ & $134(21.2)$ & & \\
\hline Secondary School & $70(35.0)$ & $278(44.0)$ & $0.6(0.4-0.9)$ & 0.03 \\
\hline Primary school & $78(39.0)$ & $217(34.3)$ & $0.9(0.6-1.4)$ & 0.71 \\
\hline Illiterate & $3(1.5)$ & $3(0.5)$ & $4.5(0.8-25.9)$ & 0.09 \\
\hline \multicolumn{5}{|l|}{ Environmental conditions } \\
\hline \multicolumn{5}{|l|}{ House walls plastered } \\
\hline Yes & $174(95.6)$ & $594(96.1)$ & & \\
\hline No & $8(4.4)$ & $24(3.9)$ & $1.8(0.9-3.9)$ & 0.12 \\
\hline \multicolumn{5}{|l|}{ Floor construction } \\
\hline Tiles/wood & $144(78.3)$ & $521(84.3)$ & & \\
\hline Other & $40(21.7)$ & $97(15.7)$ & $1.4(1.0-2.2)$ & 0.07 \\
\hline \multicolumn{5}{|l|}{ Insecticide-sprayed house } \\
\hline Yes & $134(73.6)$ & $425(69.7)$ & & \\
\hline No & $48(26.4)$ & $185(30.3)$ & $1.4(0.9-2.0)$ & 0.10 \\
\hline \multicolumn{5}{|l|}{ Open litter } \\
\hline Yes & $39(21.2)$ & $123(19.8)$ & & \\
\hline No & $145(78.8)$ & $497(80.2)$ & $1.3(0.9-1.9)$ & 0.20 \\
\hline \multicolumn{5}{|l|}{ Neighbourhood } \\
\hline Houses & $51(27.7)$ & $131(21.1)$ & & \\
\hline Houses with gardens & $118(64.1)$ & $439(70.8)$ & $0.6(0.4-0.9)$ & 0.02 \\
\hline Land & $15(8.2)$ & $50(8.1)$ & $0.6(0.3-1.2)$ & 0.14 \\
\hline \multicolumn{5}{|l|}{ Understanding the disease } \\
\hline \multicolumn{5}{|l|}{ Regarding the vector } \\
\hline Yes & $24(13.0)$ & $68(11.0)$ & & \\
\hline No & $160(87.0)$ & $552(89.0)$ & $1.4(0.9-2.2)$ & 0,18 \\
\hline \multicolumn{5}{|c|}{ Regarding the reasons why dogs have to be eliminated } \\
\hline Yes & $150(81.5)$ & $462(74.4)$ & & \\
\hline No & $34(18.5)$ & $159(25.6)$ & $1.6(1.0-2.4)$ & 0.03 \\
\hline \multicolumn{5}{|c|}{ Owner arranged examination of dog } \\
\hline Yes & $132(72.1)$ & $488(80.0)$ & & \\
\hline No & $51(27.9)$ & $122(20.0)$ & $0.7(0.5-1.1)$ & 0.11 \\
\hline
\end{tabular}

*Brazilian minimum wages (Brazilian monthly minimum wage $=\mathrm{U} \$ 262$ ).

doi:10.1371/journal.pntd.0001291.t002

salary were twice as likely to be infected in comparison with dogs of higher-income families (three minimum salaries). In this context, family income is a proxy variable of socioeconomic status and is probably associated with the structure of the most vulnerable domiciles. Indeed, Oliveira et al. [26] demonstrated an association between HVL and family income following a study in the metropolitan area of Belo Horizonte. These data are also consistent with literature confirming that $\mathrm{VL}$ is more frequent in areas of precarious socioeconomic status [45].
In general, dog owners showed little knowledge of phlebotomine sand flies. Interestingly, however, dogs whose owners knew about the vector were twofold more likely to acquire the infection than those whose owners were not familiar with the insect. This variable can be understood as an indirect measure of exposure to phlebotomines and shows the importance of using proxy. A similar observation has been reported by Moreno et al. [44], who noted that in the metropolitan area of Belo Horizonte, the likelihood of being infected by Leishmania is six times greater for 
Table 3. Risk factors for Leishmania infantum infection in seronegative dogs according to hierarchical model, Brazil 2008.

\begin{tabular}{lll}
\hline Variable & $\begin{array}{l}\text { Crude Odds Ratio } \\
\mathbf{( 9 5 \% ~ C l )}\end{array}$ & $\begin{array}{l}\text { Adjusted Odds Ratio } \\
\mathbf{( 9 5 \% ~ C I )}\end{array}$ \\
\hline $\begin{array}{l}\text { Family income } \\
<2 \text { wages versus }>3 \text { minimum wages* } \\
\begin{array}{l}\text { Knowledge of the owner regarding the vector } \\
\text { yes versus no }\end{array}\end{array}$ & $2.4(1.5-3.9)$ & $2.3(1.4-3.8)$ \\
$\begin{array}{l}\text { Dog staying predominantly in the backyard } \\
\text { yes versus no } \\
\begin{array}{l}\text { CVL serological examination previously } \\
\text { no versus yes }\end{array}\end{array}$ & $1.4(0.9-2.2)$ & $1.9(1.1-3.4)$ \\
\hline
\end{tabular}

*Brazilian minimum wages (Brazilian monthly minimum wage $=\mathrm{U} \$ 262$ ).

doi:10.1371/journal.pntd.0001291.t003

people who have seen the vector than for those who have not. A high density of Lu. longipalpis was observed in the present study area [38], so it is not surprising that the most respondents had noted the presence of the vector in their residences and neighborhood.

Dogs that usually lived in the backyard were twice as likely to acquire the infection as those that remained inside the house. According to Galvez et al. [46], living outdoors is significantly associated with serological positivity for the parasite among canines. In the recent survey performed in Granada, Spain, dogs that slept outdoors were at greater risk than those sleeping indoors because of vector density [47]. On the other hand, Cabrera et al. [48] reported that the risk of infection by CVL is similar for dogs that live within the perimeter of a residence and those that wander the streets or woods.

To reduce the risk of GVL, some preventive measures may be adopted, including the maintenance of dogs in closed kennels during periods of intense vector activity, the reduction of microenvironmental factors that favor the development of the vector in the residence, and the use insecticide-impregnated collars $[22,49]$. However, the implementation of such measures depends not only on the degree of awareness of the dog owner about the disease but, mainly, on socioeconomic issues, because the most affected population could not afford to leave their dogs in kennels or buy impregnated collars. Only $35.5 \%$ of owners knew of the important role of dogs in the transmission of Leishmania, and $45.5 \%$ had knowledge of the symptoms of CVL, although 22.8\% reported previous ownership of a dog that had contracted CVL.

Animals serologically tested by the CPVL previously were less likely to be infected. This finding indicates that seropositive dogs have been removed regularly by the control measures and that dogs that remain seronegative in successive tests are more likely to be CVL-free. Unfortunately, however, the replacement of dogs within the study area is frequent, and these animals would be more susceptible to infection by $L$. infantum [50]. The mean age of infected dogs was 49.8 (SD 41.3) months, whereas the mean age of non-infected dogs was 54.5 (SD 39.0) months. One possible explanation for this result is that the CPVL had removed seropositive dogs during the canine survey. Therefore, PCR was detecting $L$. infantum infection early, in younger dogs. Although the univariate analysis was significant, dog age was not associated with L. infantum infection. Galvez et al.[46] examined the age at which seroprevalence showed a bimodal distribution, with one peak appearing in the young dogs ( $1-2$ years $)$ and a second, more evident, peak among the older dogs (7-8 years). On the other hand, França-Silva et al. [8] observed that the prevalence of infection was not correlated with dog age.
The emergence of leishmaniasis in Belo Horizonte dates from the late 1980s, when the disease spread from areas marked by poor socioeconomic conditions [51]. At the present time, the disease is increasing, and VL has been detected in all regions of the city [38]. Indeed, the urbanization of VL is a current reality in many Brazilian cities.

We tried to identify domiciles that were most vulnerable to the presence of the vector and occurrence of infection. However, no variable related to households was maintained in the final model. In a study conducted in Northeastern Brazil, the risk of HVL was greater in residences that lacked sewage services and garbage collection [25]. In the present study, no influence of such factors on the prevalence of CVL was found, as $99 \%$ of domiciles were served by a main sewage connection and nearly all received garbage collection.

Even though our sampling procedure was not probabilistic, the studied households were sampled from a census survey, and the investigated blocks are representative of the northwest sanitary district. This study was not designed to evaluate a representative sample of Belo Horizonte but to assess the prevalence of infection by PCR-RFLP in seronegative dogs and identify risk factors for infection in these animals. However, the northwest sanitary district is representative of the city, with buildings, commerce, residences and green areas. Moreover, the main limitation of a cross-sectional study in identifying risk factors is that it does not permit causal inferences because time factors were not evaluated.

Although it is not easy to attribute the associated factors with new measures that can be adopted by CPVL, it is necessary to better investigate the factors associated with VL expansion in urban areas. Improved understanding of urbanization processes in large cites such Belo Horizonte can help the CPVL to adopt measures that are more effective at controlling the spread of the disease. It is important to emphasize that the control of HVL depends on the management of CVL because dogs are the main urban reservoir of Leishmania and represent the main source of phlebotomine infection.

The Control Program in Brazil used ELISA for screening and IFAT as a confirmatory test to identify seropositive dogs which are them euthanized. Due to the low level of humoral immune response, some of the infected dogs by $L$. infantum could not be detected. Therefore, using only seronegative dogs, this paper focuses on those animals that are positive by PCR and are not identified by the control program. Considering that the currently available serologic methods lack sufficient sensitivity and/or specificity to accurately identify all infected dogs, the employment of molecular diagnosis to detect the CVL infection before antibody production could be an efficient alternative. This study showed for 
the first time the identification of factors associated with early stage of CVL in animals seronegative with PCR-positive for L. infantum and therefore could contribute to better understanding of the involvement of this reservoir in urban-VL epidemiology. Additionally, for better investigation of the factors associated with VL expansion in urban areas further studies are required using a cohort study approach.

\section{Acknowledgments}

We thank the people from the Secretaria Municipal de Saúde de Belo Horizonte, Minas Gerais, for their cooperation, logistical support and special dedication to this work.

\section{References}

1. Desjeux P (2004) Leishmaniasis: current situation and new perspectives. Comp Immunol Microbiol Infect Dis 27: 305-318.

2. Brasil (2006) Manual de vigilância e controle da leishmaniose visceral, 1th ed. Secretaria de Vigilância em Saúde, Brasília. Available at: http://portal.saude.gov. br/portal/arquivos/pdf/manual_leish_visceral2006.pdf Accessed December 8.

3. Oliveira CD, Morais MH, Machado-Coelho GL (2008) Visceral leishmaniasis in large Brazilian cities: challenges for control. Cad Saude Publica 24: 2953-2958.

4. Killick-Kendrick R (1999) The biology and control of phlebotomine sand flies. Clin Dermatol 17: 279-289.

5. Molina R, Amela C, Nieto J, San-Andres M, Gonzalez F, et al. (1994) Infectivity of dogs naturally infected with Leishmania infantum to colonized Phlebotomus perniciosus. Trans R Soc Trop Med Hyg 88: 491-493.

6. Mohebali M, Hajjaran H, Hamzavi Y, Mobedi I, Arshi S, et al. (2005) Epidemiological aspects of canine visceral leishmaniosis in the Islamic Republic of Iran. Vet Parasitol 129: 243-251.

7. Moreno J, Alvar J (2002) Canine leishmaniasis: epidemiological risk and the experimental model. Trends Parasitol 18: 399-405.

8. Franca-Silva JC, da Costa RT, Siqueira AM, Machado-Coelho GL, da Costa CA, et al. (2003) Epidemiology of canine visceral leishmaniosis in the endemic area of Montes Claros Municipality, Minas Gerais State, Brazil. Vet Parasitol 111: 161-173.

9. Malaquias LC, do Carmo Romualdo R, do Anjos JB, Jr., Giunchetti RC, Correa-Oliveira R, et al. (2007) Serological screening confirms the re-emergence of canine leishmaniosis in urban and rural areas in Governador Valadares, Vale do Rio Doce, Minas Gerais, Brazil. Parasitol Res 100: 233-239.

10. Rondon FC, Bevilaqua CM, Franke CR, Barros RS, Oliveira FR, et al. (2008) Cross-sectional serological study of canine Leishmania infection in Fortaleza, Ceara state, Brazil. Vet Parasitol 155: 24-31.

11. Lopes EGP, Magalhães DF, Silva JA, Haddad JPA, Moreira EC (2010) Distribuição temporal e espacial da leishmaniose visceral em humanos e cães em Belo Horizonte-MG, 1993 a 2007 [Temporal and spatial distribution of leishmaniasis in humans and dogs from Belo Horizonte-MG, 1993-2007]. Arq Bras Med Vet Zootec 62: 1062-1071.

12. D'Andrea LAZ, Camargo-Neves VLF, Sampaio SMP, Kronka SN, Sartor IF (2009) American visceral leishmaniasis: disease control strategies in dracena microregion in alta paulista, SP, Brazil. J Venom Anim Toxins incl Trop Dis 15: 305-324.

13. Monteiro EM, da Silva JC, da Costa RT, Costa DC, Barata RA, et al. (2005) Visceral leishmaniasis: a study on phlebotomine sand flies and canine infection in Montes Claros, State of Minas Gerais]. Rev Soc Bras Med Trop 38: 147-152.

14. de Andrade HM, Reis AB, dos Santos SL, Volpini AC, Marques MJ, et al. (2006) Use of PCR-RFLP to identify Leishmania species in naturally-infected dogs. Vet Parasitol 140: 231-238.

15. Solano-Gallego L, Morell P, Arboix M, Alberola J, Ferrer L (2001) Prevalence of Leishmania infantum infection in dogs living in an area of canine leishmaniasis endemicity using PCR on several tissues and serology. J Clin Microbiol 39: $560-563$.

16. Rosario EY, Genaro O, Franca-Silva JC, da Costa RT, Mayrink W, et al. (2005) Evaluation of enzyme-linked immunosorbent assay using crude Leishmania and recombinant antigens as a diagnostic marker for canine visceral leishmaniasis. Mem Inst Oswaldo Cruz 100: 197-203.

17. Ashford DA, David JR, Freire M, David R, Sherlock I, et al. (1998) Studies on control of visceral leishmaniasis: impact of dog control on canine and human visceral leishmaniasis in Jacobina, Bahia, Brazil. Am J Trop Med Hyg 59: 53-57.

18. Braga MD, Coelho IC, Pompeu MM, Evans TG, MacAullife IT, et al. (1998) [Control of canine visceral leishmaniasis: comparison of results from a rapid elimination program of serum-reactive dogs using an immunoenzyme assay and slower elimination of serum-reactive dogs using filter paper elution indirect immunofluorescence]. Rev Soc Bras Med Trop 31: 419-424.

19. Quinnell RJ, Courtenay O, Davidson S, Garcez L, Lambson B, et al. (2001) Detection of Leishmania infantum by PCR, serology and cellular immune response in a cohort study of Brazilian dogs. Parasitology 122: 253-261.

\section{Author Contributions}

Conceived and designed the experiments: ABR MJM MC. Performed the experiments: WG-V VMV BMR RDdOA-S LESR SLB MHFM. Analyzed the data: WC-V ABR MC. Contributed reagents/materials/ analysis tools: ABR MC. Wrote the paper: WC-V ABR MJM MG. Responsible for the molecular methods: MJM VMV. Responsible for serological methods: ABR. Responsible for analysis: MC.

20. Oliva G, Scalone A, Foglia Manzillo V, Gramiccia M, Pagano A, et al. (2006) Incidence and time course of Leishmania infantum infections examined by parasitological, serologic, and nested-PCR techniques in a cohort of naive dogs exposed to three consecutive transmission seasons. J Clin Microbiol 44: 1318-1322.

21. Solano-Gallego L, Koutinas A, Miro G, Cardoso L, Pennisi MG, et al. (2009) Directions for the diagnosis, clinical staging, treatment and prevention of canine leishmaniosis. Vet Parasitol 165: 1-18.

22. Baneth G, Koutinas AF, Solano-Gallego L, Bourdeau P, Ferrer L (2008) Canine leishmaniosis - new concepts and insights on an expanding zoonosis: part one. Trends Parasitol 24: 324-330.

23. Strauss-Ayali D, Jaffe CL, Burshtain O, Gonen L, Baneth G (2004) Polymerase chain reaction using noninvasively obtained samples, for the detection of Leishmania infantum DNA in dogs. J Infect Dis 189: 1729-1733.

24. Borges BK, Silva JA, Haddad JP, Moreira EC, Magalhaes DF, et al. (2008) [Assessment of knowledge and preventive attitudes concerning visceral leishmaniasis in Belo Horizonte, Minas Gerais State, Brazil]. Cad Saude Publica 24: 777-784.

25. Costa CH, Werneck GL, Rodrigues L, Jr., Santos MV, Araujo IB, et al. (2005) Household structure and urban services: neglected targets in the control of visceral leishmaniasis. Ann Trop Med Parasitol 99: 229-236.

26. Oliveira CD, Diez-Roux A, Cesar CC, Proietti FA (2006) A case-control study of microenvironmental risk factors for urban visceral leishmaniasis in a large city in Brazil, 1999-2000. Rev Panam Salud Publica 20: 369-376.

27. Moreira ED, Jr., de Souza VM, Sreenivasan M, Lopes NL, Barreto RB, et al. (2003) Peridomestic risk factors for canine leishmaniasis in urban dwellings: new findings from a prospective study in Brazil. Am J Trop Med Hyg 69: 393-397.

28. Sideris V, Karagouni E, Papadopoulou G, Garifallou A, Dotsika E (1996) Canine visceral leishmaniasis in the great Athens area, Greece. Parasite 3: $125-130$.

29. Harhay MO, Olliaro PL, Costa DL, Costa CH (2011) Urban parasitology: visceral leishmaniasis in Brazil. Trends Parasitol.

30. PBH (2010) Percentual de positividade de Leishmaniose Visceral Canina, em Belo Horizonte, 2004 a 2008. http://portalpbh.pbh.gov.br/pbh/ecp. Accessed 2009 Aug 20.

31. IBGE (2000) Censo Demográfico 2000. Agregado por setores censitários dos resultados do universo. $2^{\mathrm{a}}$ edition. < http://www.ibge.gov.br/home/mapa_site/ mapa_site.php\#download $>$. Accessed: 10 may 2011.

32. Reis AB, Teixeira-Carvalho A, Vale AM, Marques MJ, Giunchetti RC, et al (2006) Isotype patterns of immunoglobulins: hallmarks for clinical status and tissue parasite density in Brazilian dogs naturally infected by Leishmania (Leishmania) chagasi. Vet Immunol Immunopathol 112: 102-116.

33. Lowry OH, Rosebrough NJ, Farr AL, Randall RJ (1951) Protein measurement with the Folin phenol reagent. J Biol Chem 193: 265-275.

34. Degrave W, Fernandes O, Campbell D, Bozza M, Lopes U (1994) Use of molecular probes and PCR for detection and typing of Leishmania-a minireview. Mem Inst Oswaldo Cruz 89: 463-469.

35. Volpini AC, Passos VM, Oliveira GC, Romanha AJ (2004) PCR-RFLP to identify Leishmania (Viannia) braziliensis and L. (Leishmania) amazonensis causing American cutaneous leishmaniasis. Acta Trop 90: 31-37.

36. Rabe-Hesketh S, Skrondal A (2005) Multilevel and longitudinal modeling using Stata. College Station, TX: Stata Press.

37. Victora CG, Huttly SR, Fuchs SC, Olinto MT (1997) The role of conceptual frameworks in epidemiological analysis: a hierarchical approach. Int J Epidemiol 26: $224-227$.

38. Margonari C, Freitas CR, Ribeiro RC, Moura AC, Timbo M, et al. (2006) Epidemiology of visceral leishmaniasis through spatial analysis, in Belo Horizonte municipality, state of Minas Gerais, Brazil. Mem Inst Oswaldo Cruz 101: 31-38.

39. Lachaud L, Chabbert E, Dubessay P, Dereure J, Lamothe J, et al. (2002) Value of two PCR methods for the diagnosis of canine visceral leishmaniasis and the detection of asymptomatic carriers. Parasitology 125: 197-207.

40. Quaresma PF, Murta SM, Ferreira Ede C, da Rocha-Lima AC, Xavier AA, et al. (2009) Molecular diagnosis of canine visceral leishmaniasis: identification of 
Leishmania species by PCR-RFLP and quantification of parasite DNA by realtime PCR. Acta Trop 111: 289-294.

41. Oliveira GG, Santoro F, Sadigursky M (1993) The subclinical form of experimental visceral leishmaniasis in dogs. Mem Inst Oswaldo Cruz 88: 243-248.

42. Romero GA, Boelaert M (2010) Control of visceral leishmaniasis in latin america-a systematic review. PLoS Negl Trop Dis 4: e584.

43. Coura-Vital W, Marques MJ, Giunchetti RC, Teixeira-Carvalho A, Moreira ND, et al. (2011) Humoral and cellular immune responses in dogs with inapparent natural Leishmania infantum infection. Vet J Doi: 101016/ jtvjl201104005 in press.

44. Moreno EC, Melo MN, Genaro O, Lambertucci JR, Serufo JC, et al. (2005) Risk factors for Leishmania chagasi infection in an urban area of Minas Gerais State. Rev Soc Bras Med Trop 38: 456-463.

45. Werneck GL, Maguire JH (2002) Spatial modeling using mixed models: an ecologic study of visceral leishmaniasis in Teresina, Piaui State, Brazil. Cad Saude Publica 18: 633-637.
46. Galvez R, Miro G, Descalzo MA, Nieto J, Dado D, et al. (2010) Emerging trends in the seroprevalence of canine leishmaniasis in the Madrid region (central Spain). Vet Parasitol 169: 327-334.

47. Martin-Sanchez J, Morales-Yuste M, Acedo-Sanchez C, Baron S, Diaz V, et al. (2009) Canine leishmaniasis in southeastern Spain. Emerg Infect Dis 15: 795-798.

48. Cabrera MA, Paula AA, Camacho LA, Marzochi MC, Xavier SG, et al. (2003) Canine visceral leishmaniasis in Barra de Guaratiba, Rio de Janeiro, Brazil: assessment of risk factors. Rev Inst Med Trop Sao Paulo 45: 79-83.

49. Alexander B, Maroli M (2003) Control of phlebotomine sandflies. Med Vet Entomol 17: 1-18.

50. Moreira ED, Jr., Mendes de Souza VM, Sreenivasan M, Nascimento EG, Pontes de Carvalho L (2004) Assessment of an optimized dog-culling program in the dynamics of canine Leishmania transmission. Vet Parasitol 122: 245-252.

51. Borges BKA, Silva JA, Haddad JPA, Moreira EC, Magalhães DF, et al. (2009) Presença de animais associada ao risco de transmissão da leishmaniose visceral em humanos em Belo Horizonte, Minas Gerais [Animal presence and the risk for transmission of visceral leishmaniasis in Belo Horizonte, Brazil]. Arq Bras Med Vet Zootec 61: 1035-1043. 